\title{
Minor physical anomalies in familial and sporadic schizophrenia: the Maudsley family study
} T D Griffiths, T Sigmundsson, N Takei, S Frangou, P B Birkett, T Sharma, A M Reveley,
R M Murray

\begin{abstract}
Objectives-(1) To test the hypothesis that minor physical anomalies are increased in patients with schizophrenia and (2) to investigate differences in the prevalence of minor physical anomalies in patients with familial and sporadic schizophrenia and their first degree relatives.

Methods-A weighted Waldrop assessment was carried out on 214 subjects in five groups: schizophrenic patients from multiply affected families; first degree relatives of these familial schizophrenic patients; sporadic schizophrenic patients; first degree relatives of these sporadic schizophrenic patients, and normal controls. Broad and narrow criteria for abnormality were defined based on the distribution of minor physical anomalies in the control group.
\end{abstract}

Results-(1) The total schizophrenic group did not have a significant increase in minor physical anomalies using a narrow criterion of abnormality, but did when a broader criterion was used. (2) A significant increase in the proportion of subjects with an abnormally high number of minor physical abnormalities was shown in the group of sporadic schizophrenic patients (uncorrected $p<0.01$ ). Separate analyses for males and females showed a significant increase in the male sporadic group (uncorrected $p<0.05$ ), and a smaller non-significant increase in the female sporadic group. Neither the familial schizophrenic group nor either group of first degree relatives showed any significant increases in the proportion of patients with high abnormality scores.

Conclusion-This work supports prenatal developmental abnormality as a mechanism for sporadic, but not familial, schizophrenia.

(F Neurol Neurosurg Psychiatry 1998;64:56-60)

Keywords: schizophrenia; genetics; family study; minor physical anomaly; Waldrop procedure

Minor physical anomalies are subtle morphological anomalies often associated with prenatal insult. ${ }^{12}$ Minor physical anomalies have been shown to be increased in children with mental retardation and behavioural disorders, especially in boys. ${ }^{3}$ Early prenatal ectodermal insult is a compelling explanation for both minor physical anomalies and the associated brain disorders. Increased minor physical anomalies may be familial, associated with chromosomal abnormalities, or with obstetric complications, ${ }^{4}$ suggesting that a variety of intrauterine processes may be responsible.

There has been considerable recent interest in schizophrenia as a possible neurodevelopmental disorder, ${ }^{5}$ for which minor physical anomalies might serve as a marker. An early study (Goldfarb and Botstein, cited in Waldrop et $a l^{6}$ ) found increased numbers of minor physical anomalies in schizophrenic children compared with normal controls. Several subsequent studies (reviewed in Alexander et $a l^{7}$ and McGrath et $a l^{8}$ ) have also found an increase in minor physical anomalies in schizophrenia, often using a weighted scoring instrument based on distinguishing measures. In the present study, minor physical anomalies were examined in groups of non-familial (sporadic) schizophrenic patients and schizophrenic patients from multiply affected families, as well as in their first degree relatives. Murray et $a l^{9}$ and Lewis and Murray ${ }^{10}$ have advocated such a strategy as a method of identifying groups of schizophrenic patients in which genetic and environmental factors will have a greater respective aetiological role.

Our purpose was, firstly, to test the hypothesis that schizophrenia is associated with features of abnormal early development. Secondly, we wished to examine differences in the prevalence of minor physical anomalies in different types of schizophrenia. Hypotheses based on an early insult in sporadic schizophrenia ${ }^{511}$ predict an increase in minor physical anomalies in the sporadic schizophrenia group only. By contrast, if familial schizophrenia were mediated by a genetic predisposition to abnormal prenatal development, an increase in minor physical anomalies would be predicted in the group of familial schizophrenic patients and their first degree relatives. These two hypotheses are not mutually exclusive.

\section{Methods}

GROUP DEFINITIONS

Assessments were carried out on 214 subjects in five groups by a single assessor (TDG), over a period of two years. The groups comprised (1) patients with schizophrenia from multiply affected families, (2) their first degree relatives, (3) patients with schizophrenia without a family history (sporadic patients), (4) first degree relatives of sporadic schizophrenic patients, and (5) a group of normal controls. Table 1 shows group demographic data. The multiply affected and sporadic family members were recruited for the Maudsley Family Study from centres throughout the United Kingdom. Normal controls were recruited from various sources, and included spouses of family members, respondents to a 
Table 1 Group demographics

\begin{tabular}{lllllll}
\hline & $\begin{array}{l}\text { Familial } \\
\text { SCZ }\end{array}$ & $\begin{array}{l}\text { Familial } \\
\text { SCZ relative }\end{array}$ & $\begin{array}{l}\text { Sporadic } \\
\text { SCZ }\end{array}$ & $\begin{array}{l}\text { Sporadic SCZ } \\
\text { relative }\end{array}$ & Control & $p$ Value \\
\hline Number & 32 & 63 & 28 & 44 & 47 & \\
Age & $37(4.5)$ & $42(16.5)$ & $32(8.3)$ & $53(12.5)$ & $33.0(13.5)$ & $0.0001^{\star}$ \\
Sex (\% male) & 59.0 & 42.9 & 57.1 & 40.9 & 44.7 & $0.38 \dagger$ \\
Age of onset of symptoms & $20.7(4.5)$ & & $20.3(4.51)$ & & & $0.60 \ddagger$ \\
\hline
\end{tabular}

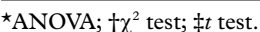

$\mathrm{p}$ Value for group differences is based on statistical tests appropriate to the nature of variables. Values are mean (SD) except for sex. SCZ=schizophrenia.

local advertisement, and members of staff at the Bethlem and Maudsley Hospital Trust.

Multiply affected families were defined as families from which more than one first or second degree relative had a diagnosis of schizophrenia, confirmed by interview for this study or by a psychiatrist at another centre. Twenty families satisfied the strict definition of a multiply affected family, and a further two families were included in the study in which this definition was met if relatives of the schizophrenic proband with schizoaffective disorder were counted as having schizophrenia. The sporadic schizophrenic families were defined by extensive interview as having no evidence of psychotic illness in first or second degree relatives. Normal control subjects also had to meet the criterion of no evidence of psychotic illness in the first or second degree relatives, although the relatives of these subjects were not interviewed.

All of the schizophrenic patients met DSM-IIIR $^{12}$ criteria for schizophrenia. Four members of the multiply affected families were rejected from the study because of the presence of chronic psychoses which did not meet DSM-IIIR criteria for schizophrenia (two cases of schizoaffective disorder, one case of psychosis not otherwise specified, and one case of bipolar disorder). Therefore, none of the patients in the non-schizophrenic groups had a psychotic illness.

\section{ASSESSMENT AND ANALYSIS}

Informed consent was obtained from all subjects. All patients in the study had a psychiatric diagnosis made by a single psychiatric rater (TS), using the structured interview SADS- $\mathrm{L}^{13}$ carried out on the same day as the physical assessment. Further information was then obtained from case notes and informants to allow a DSM-IIIR diagnosis to be made. Both the physical and psychiatric assessors were blinded to family status and to any previous psychiatric diagnosis at the time of the assessment, and were provided only with a patient identification number.
Aassessments of minor physical anomalies were carried out using a weighted scoring instrument. ${ }^{14}$ The presence of 18 items was scored and a total score calculated using the same weighting as in that study. The distribution of the Waldrop scores was found to be skewed, so that non-parametric statistics were used to compare the proportion of subjects in each group found to be abnormal. Abnormal subjects were defined as subjects satisfying a criterion defining the extreme range of scores for minor physical anomalies in the control group. Both narrow criteria (defining about 5\% of the control group as abnormal) and broad criteria (defining about $10 \%$ of the control group as abnormal) were used in the analysis. This is a novel approach; previous studies of minor physical anomalies have not examined the effect of different threshold criteria, despite there being no widely accepted normal values for the Waldrop scale. The definition of abnormality based on the Waldrop score does not have a clear cut biological basis, and we have not sought in this study to justify any particular definition. Rather, we have explored the effect of threshold criteria on the demonstration of abnormality in the schizophrenic and relative groups. Separate analyses were also carried out for males and females.

\section{Results}

The overall distribution of Waldrop scores in the male and female control groups was similar, allowing the combined control group to be used to define abnormality. A narrow definition of abnormality was used (Waldrop score of 4 or more) which defined $4.3 \%$ of the control group as abnormal. A broad definition of abnormality was also used (Waldrop score of 3 or more) which defined $10.6 \%$ of the control group as abnormal. Probability values for each of the four groups were calculated for the observed frequency of subjects with abnormal scores versus the expected frequency based on the control group and the binomial distribution. The probability values therefore represent comparisons with the control group. The

Table 2 Total group minor physical anomaly scores

\begin{tabular}{|c|c|c|c|c|}
\hline Group & $\begin{array}{l}\text { Familials } \\
\text { SCZ }\end{array}$ & $\begin{array}{l}\text { Familial } \\
\text { SCZ relative }\end{array}$ & $\begin{array}{l}\text { Sporadic } \\
\text { SCZ }\end{array}$ & $\begin{array}{l}\text { Sporadic } \\
\text { SCZ relative }\end{array}$ \\
\hline$\%$ Fulfilling narrow criterion abnormality (score $\geqslant 4$ ) & 3.1 & 3.2 & 17.8 & 0.0 \\
\hline $\mathrm{p}$ Value & 0.75 & 0.76 & $0.006^{\star}$ & 1.0 \\
\hline$\%$ Fulfilling broad criterion abnormality (score $\geqslant 3$ ) & 12.5 & 9.5 & 25.0 & 4.5 \\
\hline p Value & 0.44 & 0.67 & $0.00015^{\star}$ & 0.86 \\
\hline
\end{tabular}

$\mathrm{p}$ Value refers to the significance level based on the binomial distribution and is the probability of observing the number of abnormals seen, or more, given the probabilities based on the normal group for achieving narrow and broad criteria.

$\star$ Values reaching significance at the $5 \%$ uncorrected level.

SCZ=schizophrenia. 


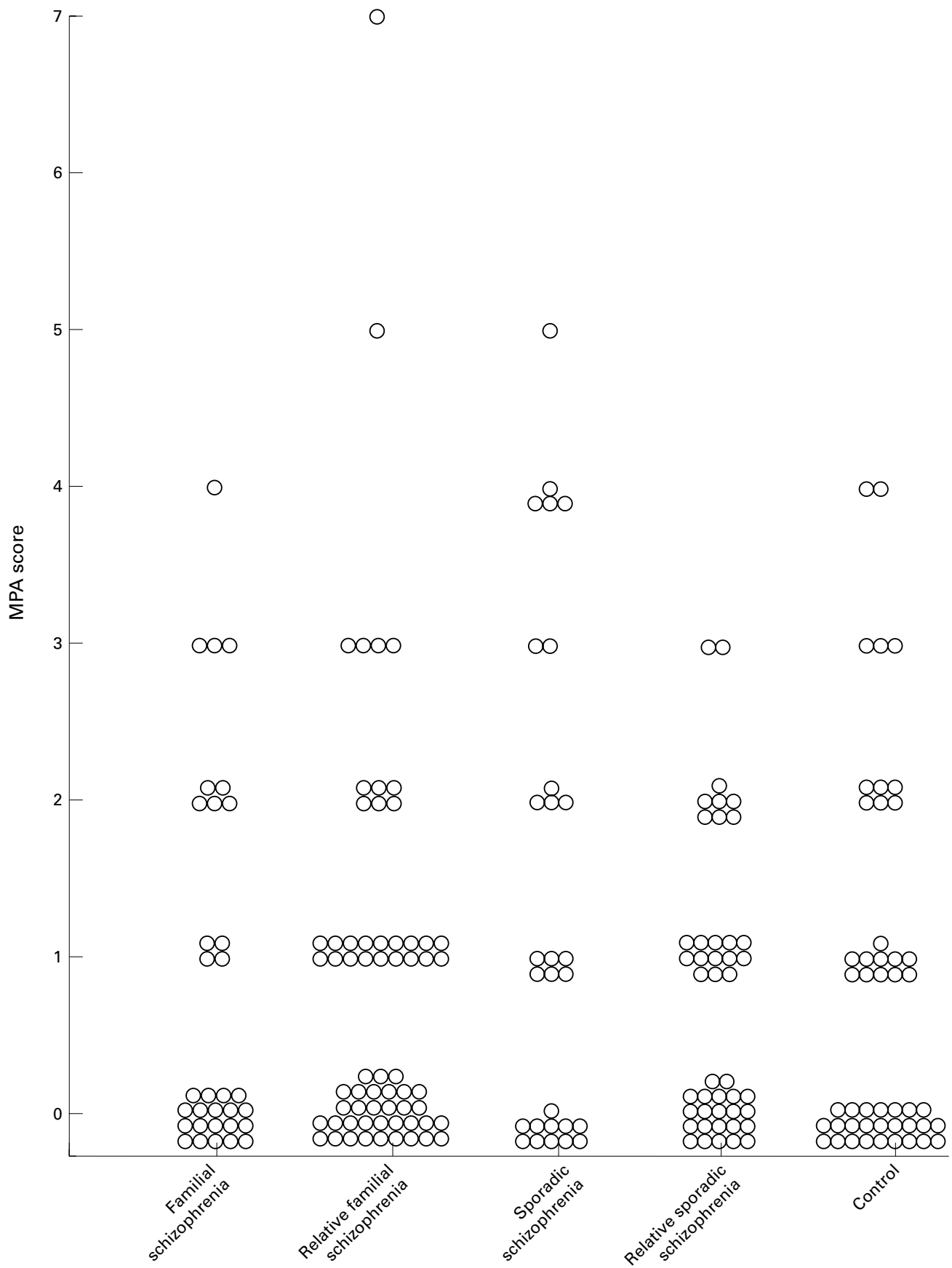

Figure 1 Distribution of minor physical anomaly (MPA) scores between groups.

percentage of subjects with abnormal minor physical anomaly scores from the total schizophrenic population in the study was $9.4 \%$ $(\mathrm{p}<0.10)$ for the narrow criterion and $18.8 \%$ $(\mathrm{p}<0.05)$ for the broad criterion.

Table 2 shows the proportions in each group defined as abnormal, and figure 1 shows the distribution of actual scores. The total group comparisons (for males and females combined) showed a significant increase only in the sporadic schizophrenic group in the proportion of patients defined as abnormal, using both broad and narrow criteria for abnormality. The comparison using the broad criterion withstood correction for multiple comparisons (corrected $\mathrm{p}<0.05$ using the Bonferroni method). No significant differences from the normal group in the proportion of subjects with high scores were found in the familial schizophrenic patients, their first degree relatives, or the relatives of sporadic schizophrenic patients.

The results, considered separately by sex for the sporadic schizophrenic group, showed the males to have a greater proportion of high minor physical anomalies scores than the females, using either broad or narrow criteria. The proportion of sporadic schizophrenic males with high minor physical anomalies scores $(17.8 \%$ by narrow and $25.0 \%$ by broad criterion) is significantly higher than that of controls (uncorrected $\mathrm{p}<0.05$ for both comparisons). The proportion 
of sporadic schizophrenic females with high minor physical anomalies scores $(16.7 \%$ by narrow and $16.7 \%$ by broad criteria) was also greater than in the control group, but not significantly so.

\section{Discussion}

SCHIZOPHRENIA

Previous studies have shown a significant increase in minor physical anomalies in schizophrenic groups compared with control groups. $^{814-16}$ The proportion of schizophrenic patients in the present study classified as abnormal using a narrow criterion is lower than in most previous studies, at less than $10 \%$ for all the schizophrenic patients in the study. In a detailed review of previous studies, Alexander et $a l^{7}$ pointed out the variation in versions of the Waldrop scale used, and in the use of weighting in previous studies. This, as well as differences in the study populations used, makes comparison between studies difficult, and emphasises the importance of including control subjects (an omission in several studies). Few previous studies have been carried out blinded, although complete blinding between schizophrenic and nonschizophrenic subjects in a face to face assessment such as the Waldrop procedure can only ever be partial. In a study that was blinded ${ }^{7}$ a more subtle difference between the schizophrenic and the control groups was shown, as here. In the previous study using parametric statistics (the distribution of scores was considered to be normal) the increase in total score in the schizophrenic compared with the control group did not reach significance ( $\mathrm{p}=0.09$, one tailed $t$ test)

No previous study has looked at the effect of different abnormality criteria; this study emphasises the importance of the threshold criterion chosen, with the total proportion of abnormal schizophrenic patients in this study being defined as significantly abnormal by one criterion but not another.

FAMILIAL AND SPORADIC SCHIZOPHRENIA One possible contributor to the variation in the results of previous studies is the use of heterogeneous populations of schizophrenic patients. The present work was carried out as part of a study specifically set up to look at differences between the phenotype of familial and sporadic schizophrenia, and the study population of schizophrenic patients includes more familial schizophrenic patients than any previous study of minor physical anomalies. Few previous studies have examined any link between familial schizophrenia and minor physical anomalies. One study that did suggested an increase in schizophrenic patients with a positive family history, ${ }^{17}$ which would be consistent with genetically mediated abnormal prenatal development in that group. That study examined a total of 41 schizophrenic patients, including 16 with positive family histories of schizophrenia defined on the basis of interview with the proband's mother, and did not include control subjects. A significant association between positive family history of schizophrenia and the presence of minor physical anomalies was found. In another study of siblings of schizophrenic patients, ${ }^{18}$ no increase in minor physical anomaly score was shown, although that study used a schizophrenic population that was not selected on the basis of positive family history. In the present study no significant increase in minor physical anomalies in the familial schizophrenic group or their first degree relatives has been shown.

By contrast, we found increases in the proportion of subjects with high minor physical anomaly scores in the sporadic schizophrenic patients. This is unlikely to be a methodological artefact as the familial and sporadic schizophrenic patients received identical assessments by the same assessor, and blinding between the two groups of schizophrenic patients was not a problem. The result for the total sporadic schizophrenic group was highly significant and withstood correction for multiple comparisons. The male schizophrenic group achieved a 0.05 significance level for both of the comparisons with controls carried out. Because that significance level is not corrected for multiple comparisons by sex, the result is strictly only significant for the case where there is a prior hypothesis about the male sex. There are, however, grounds for predicting such a result, on the basis of theories suggesting a form of "congenital" schizophrenia, more common in males, caused by abnormal prenatal development. ${ }^{19}$ This is characterised by early onset, cognitive impairment, and poor outcome, although the numbers of abnormal subjects in the present study are insufficient for detailed analysis of these characteristics. The smaller non-significant, increase in the proportion of high minor physical anomaly scores in the female schizophrenic group would still be consistent with theories of "congenital" schizophrenia, which do not exclude the possibility of females being affected. An increase in the proportion of high minor physical anomalies scores in male schizophrenic patients has previously been shown in acute schizophrenic patients ${ }^{20}$ and in a chronic refractory schizophrenic group ${ }^{7}$ in which seven out of eight schizophrenic patients satisfying a narrow criterion for abnormality were male.

\section{Conclusion}

This study has shown an increase in minor physical abnormalities in subjects with sporadic schizophrenia, especially males, but not in familial schizophrenic patients or first degree relatives of either group. This work therefore supports the notion that abnormality of prenatal development is particularly implicated in sporadic schizophrenia.

1 Lindahl E, Michelsson K. Neurodevelopmental significance of minor and major congenital anomalies in neonatal high risk children. Neuropediatrics 1986;17:86-93.

2 Cantor-Graae E, McNeil TF, Torrey EF, Quinn P, Bowler A, Sjostrom K, et al. Link between pregnancy complications and minor physical anomalies in monozygotic twins discordant for schizophrenia. Am f Psychiatry 1994;151:

Firestone P, Peters S. Minor physical anomalies and behavor in children: a review. F Autism Dev Disord 1983;13:411 
4 Firestone P, Prabhu AN. Minor physical anomalies and obstetrical complications: their relationship to hyperactive,
psychoneurotic, and normal children and their families. $\mathscr{f}$ psychoneurotic, and normal children and

5 Weinberger DR. Schizophrenia. From neuropathology to development. Lancet 1995;346:552-57.

6 Waldrop MF, Pederson FA, Bell RQ. Minor physical anomalies and behaviour in preschool children. Child Dev 1968;39:391-400.

7 Alexander RC, Mukherjee S, Richter J, Kaufmann CA Minor physical anomalies in schizophrenia. $\mathcal{F}$ Nerv Ment Dis 1994;182:639-44.

$8 \mathrm{McGrath}$ JJ, van Os J, Hoyos C, Jones PB, Harvey I, Murray RM. Minor physical anomalies in psychoses: associations with clinical and putative aetiological variables. Schizophr Res 1995;18:9-20.

9 Murray R, Lewis SW, Revely AM. Towards an aetiological classification of schizophrenia. Lancet 1985;i:1023-6.

10 Lewis SW, Murray RM. Obstetric complications, neurodevelopmental deviance, and risk of schizophrenia. F Psychiatr Res 1987;21:413-21.

11 Murray RM, O'Callaghan DJ, Lewis S. A neurodevelopmental approach to the classification of schizophrenia. Schizophr Bull 1992;18:319-32.

12 American Psychiatric Association. Diagnostic and statistical manual of mental disorders. Washington: American Psychiatric Association, 1987.
13 Spitzer RL, Endicott J. Schedule for affective disorders and schizophrenia. New York: New York State Psychiatric Instischizophrenia.

14 Green MF, Satz P, Gaier DJ, Ganzell S, Kharabi F. Minor physical anomalies in schizophrenia. Schizophr Bull 1989; 15:91-9.

15 Guy JD, Majorski LV, Wallace CJ, Guy MP. The incidence of minor physical anomalies in adult male schizophrenics. Schizophr Bull 1983;9:571-82.

16 Green MF, Bracha HS, Satz P, Christenson CD. Preliminary evidence for an association between minor physical anomalies and second trimester neurodevelopment in anomalies and second trimester neurodevelo

17 O'Callaghan E, Larkin C, Kinsella A, Waddington J. Familial, obstetric, and other clinical correlates of minor physical anomalies in schizophrenia. Am f Psychiatry 1991;148: $479-83$.

18 Green MF, Satz P, Christenson C. Minor physical anomalies in schizophrenia patients, bipolar patients, and their siblings. Schizophr Bull 1994;20:433-40.

19 Castle DJ, Murray RM. The neurodevelopmental basis of sex differences in schizophrenia. Psychol Med 1991;21:56175 .

20 Nizamie SH, Nizamie A, Sangma MW, Sharma PL. Soft neurological signs and minor physical abnormalities in schizophrenia. Ind f Psychiatry 1989;31:230-7. 